Imad Sadiq Marouf

BDS, (Master student)

Atalla F. Rejab

BDS., MSc, FIBMFS.(Asst.Prof.)

\section{Effects of Local Application of Platelet Rich Fibrin on Postoperative Sequelae after Surgical Removal of Impacted Lower Third Molars.}

Erbil Health Directorate, MOH, Iraq

Department of Oral and Maxillofacial Surgery College of Dentistry, University of Mosul

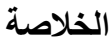

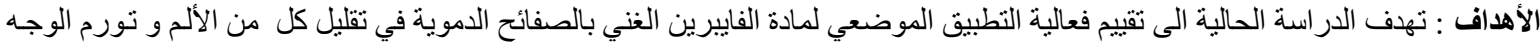

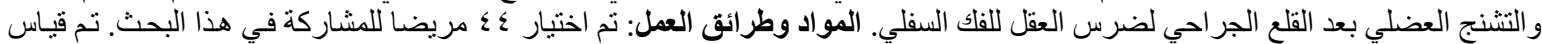

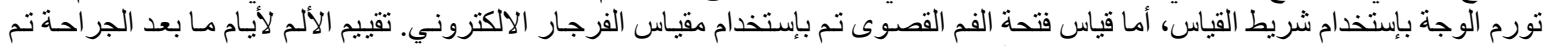

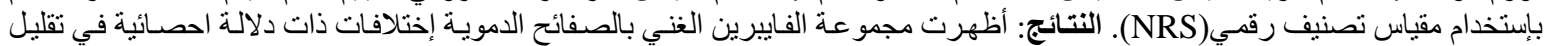

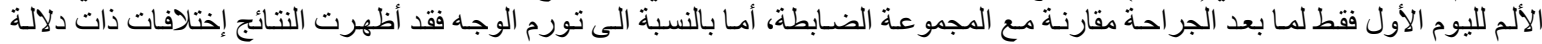

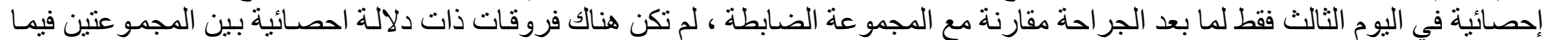

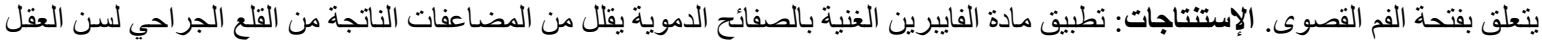

\begin{abstract}
Aims: The goals of this research was to evaluate the effects of Platelet Rich Fibrin (PRF) in reducing postsurgical complications as pain, swelling, and trismus after surgical extraction of impacted lower third molars. Materials and Methods: A total of 44 patients who fulfilled the inclusion criteria were chosen to take part in this research. Postoperative pain was assessed using a numerical rating scale (NRS). Facial swelling was measured by a modification of tape measure method. To assess trismus, the maximal interincisal mouth opening was measured by using a digital caliper scale (electronic vernier). Results: In the Platelet Rich Fibrin PRF group; the results showed a significant difference of levels of pain experienced (NRS) in the $1^{\text {st }}$ postoperative day in comparison to the control group. In regard to post-operative swelling; a significant decrease in the $3^{\text {rd }}$ postoperative day was observed in comparison to the control group. With regard to trismus; no significant differences between groups regarding interincisal mouth opening was noticed. Conclusions: The application of PRF reduces the severity of the immediate postoperative sequelaes.
\end{abstract}

Keywords: Mandibular third molar, PRF, postoperative sequelae.

Marouf IS., Rejab AF. Effects of Local Application of Platelet Rich Fibrin on Postoperative Sequelae after Surgical Removal of Impacted Lower Third Molars.. Al-Rafidain Dent J. 2020; 20(2):165-176.

DOI: 10.33899/rden.2020.126736.1025 @2020, College of Dentistry, University of Mosul 


\section{INTRODUCTION}

The main complications that may follow the removal of mandibular third molars by surgery are inflammation, delayed wound healing, facial swelling, pain, and trismus. Multiple studies have focused on reducing such complications $^{(1)}$.

Some of these studies concentrated on the use of drugs. For example, studies have demonstrated the beneficial effect of the use of nonsteroidal and steroidal anti-inflammatory drugs following surgery in minimizing odema and trismus ${ }^{(2,3)}$. Nevertheless, these drugs may result in significant systemic side effects and are contraindicated in some patients due to their potential side effects such as delayed wound healing, adrenal suppression, and increased susceptibility to infection ${ }^{(4,5)}$. These issues have encouraged researchers to look for biological alternatives such as platelet rich fibrin.

Platelet rich fibrin (PRF) clots, were developed by Choukroun et al. ${ }^{(6)}$. Platelet rich fibrin consists of a polymerized fibrin matrix in a trimolecular system containing platelets, leukocyte, cytokines, and circulating stem cells $^{(7)}$. Such a complex makes PRF a curative biomaterial that favors soft tissue and bone regeneration ${ }^{(8)}$. Several studies have shown that PRF has facilitated the healing of wounds such as following the removal of cysts, sinus augmentations and periodontal defects ${ }^{(6,9,10)}$.

The goal of this clinical trial was to investigate whether there is any beneficial value of local application of platelet rich fibrin clot on the postoperative swelling, pain, and trismus.

\section{MATERIALS AND METHODS}

\section{Patient selection:}

The study was a randomized, blinded, prospective study conducted at Erbil Dental Collective, Erbil, Iraq. Forty four patients aged between 18-29 years old were enrolled in this study following an informed verbal and written consent. The patients had either (vertical, mesioangular or horizontal) types of impaction according to Winter's classification and class II level B according to Bell and Gregory classification of impaction with partial or total bone cover.

Inclusion criteria were:

1- Patients that fulfilled the research demands including follow-up sessions and informed signing of consent.

2-Patients without systemic diseases.

3-Patient with no history of bleeding problems.

4- Patients free from allergies.

Exclusion criteria:

1-Patients on chronic medications such as steroidal and non-steroidal anti-inflammatory drugs, antihistamines, and other drugs that might affect evaluation of postoperative response.

2- Presence of acute infection such as pericoronitis and / or pain on the tooth site.

3-Pregnant and lactating women. 
4- Patients that fulfilled the demands, but at surgery the procedure take more than one hour time.

\section{Study design}

In order to minimize differences, all patients were operated by the same oral surgeon with a standardized surgical technique and equipment. Patients were divided randomly into 2 groups: study group and control group. In the study group (22 patients) platelet rich fibrin clot applied into the socket, and in the control group (22 patients) nothing was applied into the socket.

\section{Preparation of PRF}

Prior to giving anesthesia, 2 tubes of ten $\mathrm{ml}$ venous blood were collected from each patient in glass coated plastic tubes (AYSET/turkey) and immediately centrifuged (800 electric centrifuge/china) at $3000 \mathrm{rpm}$ for 10 minutes according to Choukroun's method. At completion of centrifugation cycle, the tubes were collected and caps of tubes removed. The blood sample separates into three visible layers: an acellular plasma at the top of the tube; a strongly polymerized fibrin clot is formed in the middle; and blood cells (red corpuscle base) are gathered at the bottom of the test tube, as shown in Figure (1).

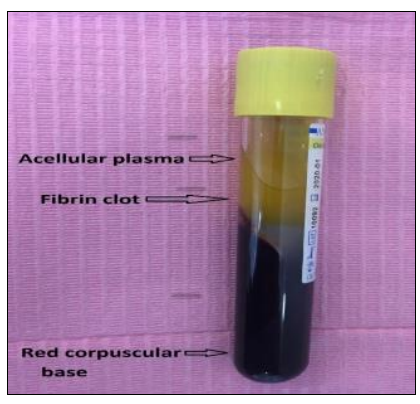

Figure (1): Glass coated plastic tube with three layers: Top layer (acellular plasma); Middle layer (PRF clot); Basal layer (red corpuscular base).

The tubes were placed in a tube rack, allowing the formed clot to mature for approximately 4-8 minutes ${ }^{(11)}$. The middle layer (PRF clot) was removed using sterile tweezers and separated by scissors from the underlying red corpuscular base, as shown in Figure (2).

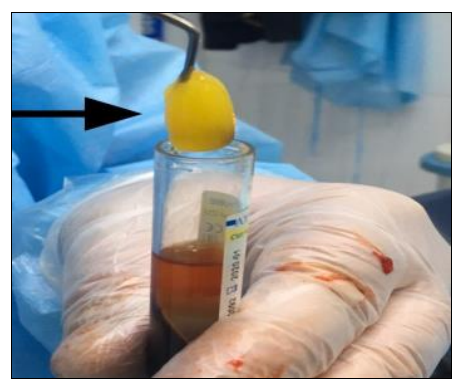

Figure (2): The middle layer (PRF clot) removed by using sterile tweezers 


\section{Surgical procedure:}

Routine regional anesthesia was applied including inferior alveolar nerve block together with buccal infiltration anesthesia. Two cartilages of lidocaine hydrochloride $2 \%$ solution with 1:80.000 epinephrine (septodent, France) were used. After incision, a mucoperiosteal soft tissue flap was reflected laterally and bone osteotomy with straight handpiece bur coupled with copious saline irrigation was done. Sometimes according to type of tooth angulation as in horizontal type, sectioning and separation of tooth crown was done. Following tooth extraction, sharp edges were smoothed with bone file, the socket irrigated and debrided mechanically. In the study group, platelet rich fibrin clot was removed with sterile tweezers and separated from the underlying red corpuscular base by using scissors and then transferred to the extraction socket, as shown in Figure (3).

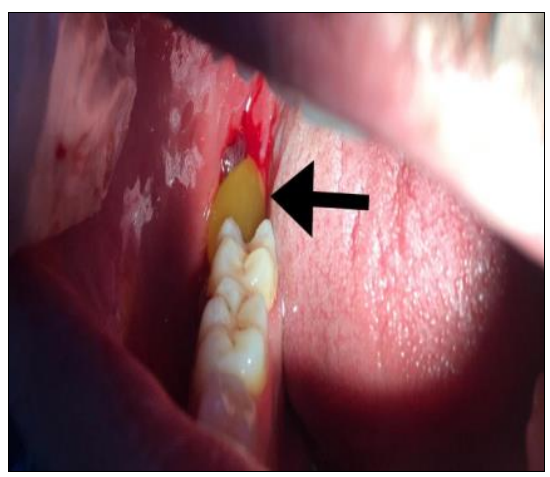

Figure (3): PRF clot transferred by sterile tweezers to the bony socket.

Nothing was applied in the control group bony socket. The flap was repositioned and sutured with silk 3/0. Gauze pressure packs were applied to the operation site to aid in hemostasis. All patients were instructed to eat soft and cold diet for the first 24 hours after operation and instructed not to gargle for the first postoperative day. Postoperatively, amoxicillin $1 \mathrm{gm}$ twice per day for 5 days with paracetamol $500 \mathrm{mg}$ every eight hours for 2 days after operation was given to each patient.

\section{Postoperative evaluation:}

Postoperative evaluation of swelling, pain, and trismus were done for all patients.

Postoperative assessment of facial swelling was taken with a modification of the tape measure method described by Gabka and Matsumara ${ }^{(12)}$ before surgery as a base line and at $1^{\text {st }}, 3^{\text {rd }}$, and $7^{\text {th }}$ postoperative days. Linear measurements were made from angle of mandible (AM) to:

1- Tragus (T)

2- Lateral canthous of eye (CE)

3- Lateral border of ala of nose (AN)

4- Corner of mouth (CM)

5- Soft tissue pogonion $(\mathrm{P})$. 
Five different measurements were operation and on the $1^{\text {st }}, 3^{\text {rd }}$, and $7^{\text {th }}$ days after recorded. All measurements were taken before operation ${ }^{(13)}$, as shown in Figure (4).

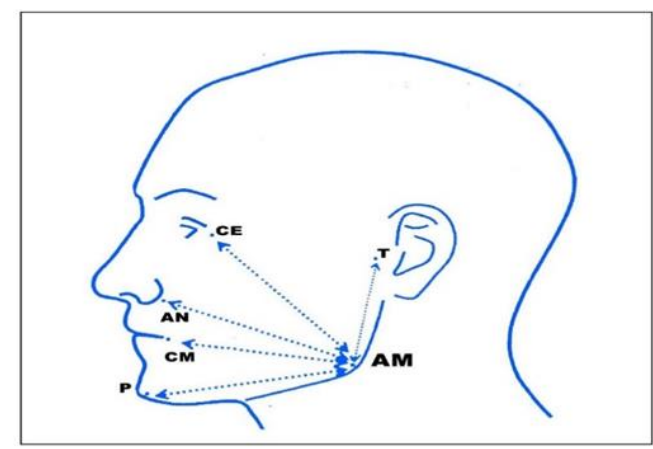

Figure (4): The measurement points AM: Angle of mandible, T: Tragus, CE:

Lateral conner of the eye, AN: Lateral border of ala of nasi, CM: Corner of the mouth, P: Soft tissue pogonion

Measuring postoperative pain was Statistical analysis was carried out using Social recorded using a numerical pain scale ${ }^{(14)}$ Sciences Statistics System (SPSS). Descriptive (NRS), which has 10 units number line marked statistics including mean values and standard by degrees. Score of 0 indicated "absence of deviations were determined for all variables in pain" and score of 10 indicated "excessive the PRF and control groups. Data were initially pain" while intermediate scores indicated "moderate pain".

The patients were educated about the meaning of scores at the beginning and were asked to express their intensity of pain by placing a mark on the scale. Pain measurements was done on the $1^{\text {st }}, 3^{\text {rd }}$, and $7^{\text {th }}$ postoperative days. Pre and postoperative degree of mouth opening were used to determine the degree of trismus. Maximal interincisal mouth opening was measured using an electronic digital caliper (electronic vernier /china). Postoperative measurements were done on $1^{\text {st }}, 3^{\text {rd }}$, and $7^{\text {th }}$ days.

\section{Statistical analysis} tested for normal distribution using the Shapiro-Wilk test. The kruskal Wallis test and Friedman test were used for the comparison of mean pain scores. Additionally, Mann-Whitney $\mathrm{U}$ test and repeated measures test were used to assess statistical differences between groups for non-normally distributed variables (swelling and trismus). For all tests, a probability of less than 0.05 for the $95 \%$ confidence level was selected as the level of significance

\section{RESULTS}

A total of 44 patients (15 male: 29 female) were included in this study. The age range was 18-29 years; median age was 24 years, and mean \pm SD age was $(23.9 \pm 3.2)$. Patients distributed equally and without bias into two 
groups: Control and PRF. Patients were recalled on the postoperative $1^{\text {st }}, 3^{\text {rd }}$, and $7^{\text {th }}$ days after surgical extraction of impacted mandibular third molar to evaluate pain, facial swelling, and trismus. Pain scores on NRS are shown in Table (1).

Table (1): Pain scores on NRS for postoperative 1st, 3rd, and 7th days for in Control and PRF groups

\begin{tabular}{ccccc}
\hline \multirow{2}{*}{ Groups } & \multicolumn{3}{c}{ Postoperative pain score } & \\
\cline { 2 - 4 } Control & $\begin{array}{c}\text { 1st Day } \\
\text { Mean } \pm \text { SD }\end{array}$ & $\begin{array}{c}\text { 3rd Day } \\
\text { Mean } \pm \text { SD }\end{array}$ & $\begin{array}{c}\text { 7th Day } \\
\text { Mean } \pm \text { SD }\end{array}$ & Friedman test \\
\hline PRF & $4.95 \pm 2.68$ & $3.68 \pm 2.42$ & $1.68 \pm 2.30$ & $\begin{array}{c}\text { Chi-Square }=24.072 \\
\mathrm{p}=0.000^{*}\end{array}$ \\
Kruskal- & $\begin{array}{c}\mathrm{H}=11.973 \\
\mathrm{p}=0.001 *\end{array}$ & $\begin{array}{c}\mathrm{H}=4.087 \\
\mathrm{p}=0.051\end{array}$ & $\begin{array}{c}\mathrm{H}=0.301 \\
\mathrm{p}=0.583\end{array}$ & $\begin{array}{c}\mathrm{Chi}-\mathrm{Square}=37.013 \\
\mathrm{p}=0.000^{*}\end{array}$ \\
\hline Wallis test & $2.27 \pm 1.58$ & $0.82 \pm 1.18$ &
\end{tabular}

$(\mathrm{H})$

*Statistically significant at confidence level 95\%

On the $1^{\text {st }}, 3^{\text {rd }}$, and $7^{\text {th }}$ postoperative $\quad(\mathrm{p}=0.001)$. Assessment of facial swelling for days, NRS scores decreased significantly in each patient on each postoperative day was both groups over postoperative days with $\mathrm{p}$ determined by finding the mean differences value $(\mathrm{p}=0.000)$. However, the PRF group between postoperative and preoperative showed statistically significant less pain measurements. The results are presented in compared to control group just on the $1^{\text {st }}$ Table (2).

postoperative day with $\mathrm{p}$ values

Table (2): Facial swelling on postoperative 1st, 3rd, and 7th days in Control and PRF groups

\begin{tabular}{ccccc}
\hline \multirow{2}{*}{ Groups } & \multicolumn{2}{c}{ Postoperative facial swelling $(\mathrm{mm})$} & \\
\cline { 2 - 4 } & $\begin{array}{c}\text { 1st Day } \\
\text { Mean } \pm \text { SD }\end{array}$ & $\begin{array}{c}\text { 3rd Day } \\
\text { Mean } \pm \text { SD }\end{array}$ & $\begin{array}{c}\text { 7th Day } \\
\text { Mean } \pm \text { SD }\end{array}$ & Repeated Measures test \\
\hline Control & $5.85 \pm 1.38$ & $3.58 \pm 1.25$ & $0.73 \pm 0.61$ & $\begin{array}{c}\mathrm{F}=170.514 \\
\mathrm{p}=0.000^{*}\end{array}$ \\
PRF & $4.95 \pm 0.86$ & $2.50 \pm 0.74$ & $0.65 \pm 1.07$ & $\begin{array}{c}\mathrm{F}=185.206 \\
\mathrm{p}=0.000^{*}\end{array}$ \\
$\begin{array}{c}\text { Mann } \\
\text { Whitney test } \\
\text { (U) }\end{array}$ & $\begin{array}{c}\mathrm{U}=146 \\
\mathrm{p}=0.061\end{array}$ & $\begin{array}{c}\mathrm{U}=105.5 \\
\mathrm{p}=0.001^{*}\end{array}$ & $\begin{array}{c}\mathrm{U}=178 \\
\mathrm{p}=0.117\end{array}$ & \\
\hline
\end{tabular}

*Statistically significant at confidence level 95\% 
The maximum swelling in control and PRF groups were found in the $1^{\text {st }}$ postoperative day with mean swelling equal to $5.85 \mathrm{~mm}$ and $4.95 \mathrm{~mm}$ respectively. However, the level of swelling was significantly decreasing over the days of review with $(\mathrm{p}=0.00)$. On the $7^{\text {th }}$ postoperative day, the swelling in both groups returned to normal levels with values less than $1 \mathrm{~mm}$. On the other hand, patients with PRF applied in their bony sockets showed a significantly less facial swelling than control group just on the $3^{\text {rd }}$ postoperative day with $\mathrm{p}$ value $(\mathrm{p}=0.001)$.

Maximum mouth opening (interincisal distance) was recorded in every recall appointment. For each patient, the interincisal opening on each postoperative day was measured by calculating the differences between preoperative and postoperative measurements of the interincisal opening. Table (3) displays the outcomes in each group and it is clearly shown that the degree of mouth opening in both control and PRF groups significantly decreased over the postoperative $\left(1^{\text {st }}, 3^{\text {rd }}\right.$, and $\left.7^{\text {th }}\right)$ days with $(\mathrm{p}=0.00)$. However, there were no significant differences in changes in interincisal opening values between control and PRF groups with p values equal to $(0.33$, 0.159 , and 0.896 ) for the $1^{\text {st }}, 3^{\text {rd }}$, and $7^{\text {th }}$ postoperative days respectively

Table (3): Trismus on postoperative 1st, 3rd, and 7th days in Control and PRF groups

\begin{tabular}{ccccc}
\hline \multirow{2}{*}{ Groups } & \multicolumn{3}{c}{ Postoperative trismus (mm) } & \\
\cline { 2 - 4 } & $\begin{array}{c}\text { 1st Day } \\
\text { Mean } \pm \text { SD }\end{array}$ & $\begin{array}{c}\text { 3rd Day } \\
\text { Mean } \pm \text { SD }\end{array}$ & $\begin{array}{c}\text { 7th Day } \\
\text { Mean } \pm \text { sd }\end{array}$ & \\
\hline Control & $12.55 \pm 7.05$ & $9.00 \pm 6.46$ & $3.20 \pm 5.22$ & $\begin{array}{l}\mathrm{F}=24.666 \\
\mathrm{p}=0.000^{*}\end{array}$ \\
PRF & $10.57 \pm 7.61$ & $7.22 \pm 7.30$ & $2.26 \pm 2.39$ & $\begin{array}{c}\mathrm{F}=25.693 \\
\mathrm{p}=0.000^{*}\end{array}$ \\
\hline $\begin{array}{c}\text { Mann } \\
\begin{array}{c}\text { Whitney test } \\
\text { (U) }\end{array}\end{array}$ & $\begin{array}{c}\mathrm{U}=200.5 \\
\mathrm{p}=0.330\end{array}$ & $\begin{array}{c}\mathrm{U}=182 \\
\mathrm{p}=0.159\end{array}$ & $\begin{array}{c}\mathrm{U}=236.5 \\
\mathrm{p}=0.896\end{array}$ & \\
\hline *Statistically significant at confidence level 95\% & &
\end{tabular}

\section{DISCUSSION}

Impacted third molar removal by surgery causes injury of the soft tissue and bony structures in the oral cavity. Signs and symptoms of edema, pain, and limited opening of the mouth after operation can occur due to muscle spasm ${ }^{(15,16)}$.

Choukroun described PRF which is naturally prepared without the addition of thrombin ${ }^{(6)}$. PRF presents a complex of 
trimolecular architecture, with cytokines, platelets, leukocytes and circulating stem cells trapped within it ${ }^{(7)}$. PRF acts as a scaffold that is able to guide epithelial cell migration and in carrying cells involved in tissue regeneration $(17,18)$

An essential coagulation glycoprotein called (thrombospondin-1) and three main growth factors involving vascular endothelial growth factor (VEGF), transforming growth factor $\beta-1$, platelet-derived growth factor (PDGF) are released from PRF for 1 week duration after application ${ }^{(19)}$. In addition to these, PRF also secrete other types of factors of growth including epidermal growth factor, fibroblast growth factor, and three substantial proinflammatory cytokines- IL- 1b, IL-6, and TNF- $\alpha$ which is obtained with a simple centrifugation procedure. These constituents make PRF a curative biomaterial that enables optimal healing through the fast and effective regeneration of hard and soft tissues ${ }^{(6,19,20)}$.

Contrasting results regarding the clinical efficacies of PRF in oral surgical procedures have been reported in different clinical procedures ${ }^{(8,21-23)}$.

The purpose of the current study was to achieve postoperative satisfaction of patients by using an autologous biomaterial with minimal adverse reactions. After extraction, relieving of postoperative pain is an essential criterion, in addition most of the potential postoperative complications are manifested as pain. In the present study, the degree of pain was measured using the NRS. The results of this study showed that local application of PRF into the extraction sockets provide a significant decrease in pain just in the 1st postoperative day.

Many studies in the literature reported that PRF reduces symptoms of pain such as AlHamed et al. ${ }^{(24)}$ which showed that PRF significantly reduced postoperative pain and analgesic intake following surgical removal of impacted third molars for few postoperative days. This should be considered with caution because it is based on the subjective visual analogue scale, sensation of pain, and response to analgesics, which differ from person to another. In another study conducted by Kumar et al. ${ }^{(20)}$ to evaluate the effect of platelet-rich fibrin (PRF) on post-operative pain, swelling, and trismus on the first post-operative day, one month and at three months, they showed that pain was significantly lesser in the study group at the $1^{\text {st }}$ postoperative day as compared to the control group. In support to this, a study conducted by Marenzi et al. ${ }^{(25)}$ concluded that the use of L-PRF in postextraction sockets is an efficient and useful procedure for the management of postoperative pain, particularly in the first days following extraction.

$$
\text { On the contrary, Ozgul et al. }{ }^{(26)}
$$
conducted a study to assess the efficacy of PRF in the healing process by assessing changes in pain and swelling following third molar 
surgery. Their results did not reveal any beneficial effect of PRF in reducing pain between groups, where different patients made up the control and PRF groups. The null hypothesis partially dismissed the results of the study since there was no positive effect of PRF on the pain observed. Similar to this, Singh et al. ${ }^{(19)}$ placed PRF in extraction sockets following extraction and concluded that despite pain was less in the study side compared to control side, yet there was no statistical significance.

Most of the surgical procedures induce odema. Swelling usually reaches its maximum at 1-2 days after the surgery; it begins to subside on the third or fourth day and usually ends on the first week ${ }^{(27)}$. In this study, swelling was significant at the $3^{\text {rd }}$ postoperative day only. Ozgul et al. ${ }^{(26)}$ study results indicated that PRF was more effective in reducing swelling in the third day after surgery. Kumar et al. ${ }^{(20)}$ also reported that use of PRF in extraction socket resulted in reduction of odema after $1^{\text {st }}$ postoperative day.

In contrast to this, Bilginylar et al. ${ }^{(28)}$ found no differences in swelling between PRF and control groups. They attributed that for using a tape measure for measuring variations in swelling. In support to this, Ogundipe et al. ${ }^{(29)}$ used PRP gel after extraction of third molar and noticed that PRP reduced pain, swelling, and trismus compared to control group but the differences were statistically significant only for postoperative pain and was not significant for postoperative swelling.

\section{CONCLUSIONS}

PRF appears to be effective in reducing postoperative swelling and pain following third molar removal. However, the effects were significant for few postoperative days.

\section{REFERENCES}

1- Blondeau F, Daniel NG. Extraction of impacted mandibular third molars: postoperative complications and their risk factors. J Can Dent Assoc. 2007; 73(4):325

2- Van der Goes MC, Jacobs JW, Bijlsma JW. The value of glucocorticoid cotherapy in different rheumatic diseasespositive and adverse effects. Arthritis Res Ther. 2014; 16(2): S2.

3- Piecuch JF. What strategies are helpful in the operative management of third molars? J Oral Maxillofac Surg. 2012; 70(9): S25-S32.

4- Üstün Y, Erdoğan Ö, Esen E, Karsli ED. Comparison of the effects of 2 doses of methylprednisolone on pain, swelling, and trismus after third molar surgery. Oral Surg Oral Med Oral Pathol Oral Radiol Endod. 2003; 96(5): 535-539.

5- Kim K, Brar P, Jakubowski J, Kaltman S, Lopez E. The use of corticosteroids and nonsteroidal antiinflammatory 
medication for the management of pain and inflammation after third molar surgery: a review of the literature. Oral Surg Oral Med Oral Pathol Oral Radiol Endod. 2009; 107(5): 630-640.

6- Choukroun J, Adda F, Schoeffler C, Vervelle A. Une opportunité en paroimplantologie: le PRF. Implantodontie. 2001; 42:55-62.

7- Dohan David M, Choukroun Joseph, Diss Antoine, Dohan Stevey J, Dohan Anthony J, Mouhyi Jaafar, et al. Platelet-rich fibrin (PRF): a secondgeneration platelet concentrate. Part II: platelet related biologic features. Oral Surg Oral Med Oral Pathol Oral Radiol Endod. 2006; 101(3):e45-50.

8- Choukroun J, Diss A, Simonpieri A, Girard MO, Schoeffler C, Dohan SL, Dohan AJ, Mouhyi J Dohan DM. Platelet-rich fibrin (PRF): A secondgeneration platelet concentrate. Part IV: Clinical effects on tissue healing. Oral Surg Oral Med Oral Pathol Oral Radiol Endod. 2006; 101:e56-60.

9- Aroca S, Keglevich T, Barbieri B, Gera I, Etienne D. Clinical evaluation of a modified coronally advanced flap alone or in combination with a platelet rich fibrin membrane for the treatment of adjacent multiple gingival recessions: a 6-month study. J Periodontol. 2009; 80:244-52.
10- Simonpieri A, Del Corso M, Sammartino G, Dohan Ehrenfest DM. The relevance of Choukroun's plateletrich fibrin and metronidazole during complex maxillary rehabilitations using bone allograft. Part I: a new grafting protocol. Implant Dent. 2009; 18:10211.

11- Hartshorne J, Gluckman H. A comprehensive clinical review of Platelet Rich Fibrin (PRF) and its role in promoting tissue healing and regeneration in dentistry. Part II: Preparation, optimization, handling and application, benefits and limitations of PRF. international dentistry - African edition. 2016; 6(5): 34-48.

12- SchultzeS, Schmelzeisen R, Frolich JC, Schmele S. Use of ibuprofen and methylprednisolone for the prevention of pain and swelling after removal of impacted third molars. J Oral Maxillofac Surg. 1995; 53:2-7.

13- Neupert III EA, Lee JW, Philput CB, Gordon JR. Evaluation of dexamethasone for reduction of postsurgical sequelae of third molar removal. J Oral Maxillofac Surg. 1992; 50(11): 1177-1182.

14- McCaffrey M, Beebe A. Giving narcotics for pain. Nursing. 1989; 19(10):161-5.

15- Grossi GB, Maiorana C, Garramone RA, Borgonovo A, Creminelli L, 
Santoro F. Assesing postoperative discomfort after third molar surgery:A prospective study. J Oral Maxillofacial Surg. 2007; 65(5):901-17.

16- Baqain Z, Karaky AA, Sawair F, Khraisat A, Duaibis R, Rajab LD. Frequency estimates and risk factors for post-operative morbidity after third molar removal:A prospective cohort study. J Oral Maxillofac Surg. 2008; 66(11):2276-83.

17- Dohan DM, Choukroun J, Diss A, Dohan SL, Dohan AJ, Mouhyi J. Platelet-rich fibrin (PRF): A secondgeneration platelet concentrate.Part III:Leucocyte activation: A new feature for platelet concentrates? Oral Surg Oral Med Oral Pathol Oral Radiol Endod. 2006; 101:E51-5.

18- Chang YC and Zhao JH. Effects of platelet-rich fibrin on human periodontal ligament fibroblasts and application for periodontal infrabony defects. Aust Dent J. 2011; 56: 365-371.

19- Singh A, Kohli M, Gupta N. Platelet rich fibrin: a novel approach for osseous regeneration. J Maxillofac Oral Surg. 2012; 11(4):430-4.

20- Kumar N, Prasad K, Ramanujam L, K R, Dexith J, Chauhan A. Evaluation of Treatment Outcome after Impacted Mandibular Third Molar Surgery with the Use of Autologous Platelet-Rich Fibrin: A Randomized Controlled
Clinical Study. J Oral Maxillofac Surg. 2015; 73(6): 1042-1049.

21- Su CY, Kuo YP, Tseng YH, Su CH, Burnouf $T$. In vitro release of growth factors from platelet-rich fibrin (PRF): a proposal to optimize the clinical applications of PRF. Oral Surg Oral Med Oral Pathol Oral Radiol Endod. 2009; 108(1):56-61.

22- Lee JW, Kim SG, Kim JY, Lee YC, Choi JY, Dragos R, et al. Restoration of a peri-implant defect by platelet- rich fibrin. Oral Surg Oral Med Oral Pathol Oral Radiol Endod. 2012; 113(4):45963.

23- Zhang Y, Tangl S, Huber CD, Lin Y, Qiu L, Rausch-Fan X. Effects of Choukroun's platelet-rich fibrin on bone regeneration in combination with deproteinized bovine bone mineral in maxillary sinus augmentation: A histological and histomorphometric study. J Cranio-Maxillofac Surg. 2012; 40(4):321-8.

24- Al-Hamed FS, Tawfik M A-M, Abdelfadil E. Clinical effects of plateletrich fibrin (PRF) following surgical extraction of lower third molar. The Saudi Journal for Dental Research. 2017; 8(1-2): 19-25.

25- Marenzi G, Riccitiello F, Tia M, Lauro G, Sammartino G. Influence of leukocyte- and platelet-rich fibrin (LPRF) in the healing of simple 
postextraction sockets: a split-mouth study. BioMed Res Int. 2014; 2014:369273.

26- Ozgul O, Senses F, Er N, Tekin U, Tuz HH, Alkan A, Koçyiğit ID, Atıl F. Efficacy of platelet rich fibrin in the reduction of the pain and swelling after impacted third molar surgery: Randomized multicenter split-mouth clinical trial. Head Face Med. 2015; $11: 37-41$.

27- Peterson L J. Postoperative patient management. In: Peterson LJ, Ellis E, Hupp JR, Tucker MR, editors.
Contemporary oral and maxillofacial surgery. 4th ed. St. Louis: CV Mosby; 2003; P.214-20.

28- Bilginaylar K, Uyanik LO. Evaluation of the effects of platelet-rich fibrin and piezosurgery on outcomes after removal of impacted mandibular third molars. $\mathrm{Br}$ J Oral Maxillofac Surg. 2016; 54(6):629-33.

29- Ogundipe OK, Ugboko VI, Owotade FJ. Can autologous platelet-rich plasma gel enhance healing after surgical extraction of mandibular third molars? J Oral Maxillofac Surg. 2011; 69:2305-10. 